\title{
Improving Teacher Performance through Organizational Culture, Transformational Leadership and Work Motivation
}

\author{
Adi Dasmin*, Thamrin Abdullah, Sri Setyaningsih \\ Pakuan University, Bogor, Indonesia
}

*Corresponding Author: Adi Dasmin, Pakuan University, Bogor, Indonesia

\begin{abstract}
This study aims to determine the relationship between organizational culture, transformational leadership and work motivation both individually and jointly on teacher performance. The sample chosen was 144 people with the criteria of teachers having 30 years of experience teaching to the method multistage proportional random sampling of teachers of state junior high schools in South Jakarta. This study uses a survey method with a correlational approach followed by SITOREM (Scientific Identification Theory for Operational Research in Education) analysis, to reduce recommendations and determine the order of priority indicators, both indicators that must be improved or maintained. There is a positive relationship between organizational culture and teacher performance (ryl $=0.786, \rho<0.01)$, (2) there is a positive relationship between transformational leadership and teacher performance (ry2 $=0.734, \rho<0.01)$, (3) there is a positive relationship between work motivation with teacher performance (ry3 $=0.734, \rho<0.01)$, (3) there is a positive relationship between organizational culture, transformational leadership and work motivation together with teacher performance $(r y 123=0.835, \rho<0)$. SITOREM analysis shows that organizational culture variables, transformational leadership, work motivation, and performance are found to have 11 indicators that the situation is good, so it must be maintained. The better the organizational culture, the better the principal's transformational leadership, and the higher the work motivation, the higher the teacher's performance is predicted.
\end{abstract}

Keywords: Teacher Performance, Organizational Culture, Transformational Leadership and Work Motivation

\section{INTRODUCTION}

Teacher performance is essential because performance reflects the quality of knowledge, skills and intelligence possessed by a teacher, which is supported by a good attitude and character in achieving organizational goals. Improved teacher performance is a way to improve the welfare of themselves and their families.

The description of the performance of teachers of State Junior High Schools in South Jakarta can be seen from several indicators, namely accuracy, initiatives in work, the achievement of work results, use of resources, systematic in carrying out work, and creative works. The results of the survey data from the initial study of 30 teachers in a number of State Junior High Schools in South Jakarta in February 2018, obtained information that there is still a tendency that the performance of teachers of State Junior High Schools in South Jakarta is still not optimal.

Some other indications regarding the low performance of teachers, among others, teachers are still using conventional learning patterns in the old way of teaching by relying more on the lecture method, so that there is boredom in students in learning. Teachers should be more creative in carrying out the learning process by exploring and searching for ways of learning that are more effective, easily understood and liked by students which will lead to an interest in learning in students and ultimately will improve student learning achievement. The indications of the problem above are considered to be a benchmark for the still low performance of teachers of State Junior High Schools in South Jakarta.

Organizational culture is thought to be a very important component in improving the performance of a teacher. Having an organizational culture will make it easier for members to adjust to the work environment and help them know what actions should be taken in accordance with the values in the organization. Besides organizational culture factors, transformational leadership is also thought to be 
related to teacher performance. Transformational leadership is a process that shows leaders and followers trying to raise themselves to a higher level of morality and motivation. Another factor thought to influence teacher performance is work motivation. Work motivation is needed as one indicator of teacher performance. Teachers with high work motivation are expected to produce maximum performance, with motivation encouraging someone to carry out certain activities in order to achieve the expected goals.

Teachers in an organization include principals' transformational leadership, organizational culture, work motivation, teacher competence, work environment, job promotions, educational background, interests, attitudes, knowledge, job satisfaction, supervision, work discipline, and so on. However, the main targets in this study were organizational culture, transformational leadership, and teacher work motivation.

Based on the background that has been explained before, the formulation of the problem in this research variable is:

1. Is there a relationship between organizational culture and teacher performance?

2. Is there a relationship between transformational leadership and teacher performance?

3. Is there a relationship between teacher work motivation and teacher performance?

4. Is there a relationship between organizational culture, transformational leadership and teacher work motivation with teacher performance?

\section{LITERATURE REVIEW}

\subsection{Teacher Performance}

According to Dawson (2014), performance is the ability of organizations to achieve their goals by using resources efficiently and effectively. Based on these two definitions, it appears that the effectiveness and efficiency included in performance measures are inseparable notions, because the results obtained as the use of resources are more efficient or effective.

According to Adenjii (2011), employee performance is the contribution given by employees to a company that can be identified from the work of employees. The performance of individual employees is a factor that influences the success of an organization. Apart from employees being competitive advantages, they can also be liabilities or obstacles. When employees continue to leave the company, and when employees work but are not effective, then the human resources in the organization are at a loss. Employee performance that is common to most jobs includes elements, namely quantity of results, quality of results, timeliness of results, attendance and ability to work together.

\subsection{Organizational Culture}

Dele (2015) defines organizational culture is a pattern of basic assumptions created, discovered or developed by a group of people such as learning to cope with problems, adapting to external, and internal integration that can be considered valid and therefore taught to new members to be understood, thought and related to the problem. Furthermore, the level of organizational culture can be analyzed in three categories, namely: (1) Artifacts, (2) Values, and (3) Basic Assumptions. Artefacts are a reflection of the company's organizational culture that is at the surface level, and includes all phenomena that can be seen, heard and felt. Values are values that are mated and standardized so that the solutions that arise from an influential leader or individual in the organization are intended to solve the problems of the organization. The basic assumption is part of the corporate organizational culture that is at the deepest level to solve problems that have been running repeatedly and become a value that is taken for granted.

\subsection{Transformational Leadership}

Bertocci (2010) defines transformational leadership as behaviour that is able to stimulate and inspire followers to achieve results, and in the process of developing their leadership abilities, visions and goals given by their organizations, giving themselves a challenge to also innovate, solve problems, and develop leadership abilities towards subordinates through direction, mentoring, and providing 
challenges and support. "Transformational leaders, on the other hand, are those who stimulate and inspire followers to both to achieve extraordinary outcomes and, in the process, develop their own leadership capacity". The dimensions and indicators are a. Dimensions of the ideal influence with its indicators: a) behaviour and 2) nature, b. Dimensions of inspirational motivation with its indicators: 1) excitement and 2) optimism, c. Dimensions of intellectual stimulation with its indicators: 1) innovative and 2) creative, d. Dimensions of individual attention with its indicators: 1) achievement and 2) growth.

\subsection{Work Motivation}

Working motivation is the strength of energetic drive from within and outside the individual that encourages activities and gives strength that determines the goals, intensity and endurance to achieve certain goals. The dimensions and indicators of teacher work motivation are a. The intrinsic dimension consists of indicators: 1) working hard, 2) achieving work results, 3) success. b. The extrinsic dimension consists of indicators: 1) collaboration with personnel in the work environment, 2) appreciation from the environment, 3) leadership support.

\section{METHODS}

The study was conducted on state junior high school teachers in South Jakarta. The research took place from January 2019 to June 2019. This study used a survey method with a correlational approach. This study was designed to obtain information about the relationship between different variables in a population. This study examines three variables, namely the three independent variables and one dependent variable. Independent variables consist of Organizational Culture (X1), Transformational Leadership (X2) and Teacher Work Motivation (X3), while the dependent variable $(\mathrm{Y})$ is Teacher Performance.

The population of this research is all of the Junior High School teachers in South Jakarta with Civil Servant status and based on data from the South Jakarta City Education Office in 2018, and there were 2,334 teachers spread in 10 districts and 66 schools. The population are teachers with ten years of work or more, amounting to 223 people. In this study, samples were taken from affordable populations using multistage proportional random sampling. This study uses a survey method with a correlational approach followed by SITOREM analysis, to reduce recommendations and determine the order of priority indicators, both indicators that must be improved or maintained.

\section{RESUltS AND DISCUSSION}

\subsection{Relationship between Organizational Culture and Teacher Performance}

Hypothesis testing shows that there is a very significant positive relationship between organizational culture and teacher performance. Based on the calculation of the coefficient between organizational culture and teacher performance, the value of robtained $_{\mathrm{y} 1}=0.786$. This shows that organizational culture variables have a very significant correlation with teacher performance. The correlation value of 0.786 shows that the level of relationship is very strong between organizational culture and teacher performance.

The contribution of organizational culture factors on teacher performance in this study can be seen from the coefficient of determination $\mathrm{r}_{\mathrm{y} 1}^{2}=0.618$, which means that organizational culture contributes $62 \%$ to teacher performance, while the remaining $38 \%$ is determined by other variables. Based on this data, it can be said that an increase in organizational culture will affect teacher performance improvement.

Organizational culture represents a perception common of the members of the organization, or in other words, culture is a system of shared meanings. Therefore, the hope built from here is that individuals who have different backgrounds or are not at the same level in the organization will understand Organizational Culture in a similar sense. Power organization is a shared system of values and beliefs that actively influence the behaviour of members of the organization. So the definition means that organizational culture is a system in the organization that can influence its members (George,2015).

The results of this study are in line with theories from King (2016), that explain the dimensions of organizational culture from a two-dimensional perspective, the first dimension is the focus of internal 
orientation and the interests of organizational integration and the external orientation of the interests of organizational differentiation, while the second dimension is an orientation that focuses on stability and control and flexibility and flexibility(discretion). Based on the previous presentation, it can be concluded that organizational culture has a significant relationship in stimulating teacher performance, so the implication is that organizations need to be committed to improving organizational culture that supports teacher performance.

\subsection{Relationship between Transformational Leadership and Teacher Performance}

Hypothesis testing shows that there is a positive relationship which is very significant between transformational leadership and teacher performance. Based on the calculation of the correlation coefficient between transformational leadership and teacher performance, the value of robtained $_{\mathrm{y} 2}=$ 0.734 is. These results indicate that the transformational leadership variable has a very significant correlation with teacher performance. The magnitude of the correlation value of 0.734 shows that the level of relationship is very strong between transformational leadership and teacher performance. The contribution of transformational leadership factors on teacher performance can be seen from the coefficient of determination $\mathrm{r}_{\mathrm{y} 2}^{2}=0.539$ which means that organizational culture contributes $54 \%$ to teacher performance, while the remaining $46 \%$ is determined by other variables. This data shows that the contribution of transformational leadership is quite large, through strengthening intensive transformational leadership, it can improve teacher performance.

This is consistent with the theory that transformational leadership is the behaviour of a leader who is able to call moral values to his followers in an effort to increase their awareness of ethical issues and mobilize their energy and resources to reform institutions (Gibson, 1991).

This research is in line with the theory from Warren (2015), which explains that organizational mechanisms, team mechanisms, and individual characteristics build individual mechanisms in an effort to foster job performance and organizational commitment. Where in the team mechanism, there is an element of leadership. Transformational leadership motivates teachers to do work or tasks better than what subordinates want and even higher than what was previously thought. Leadership from the beginning will generate awareness and high commitment from the group towards the goals and mission of the organization and will arouse the commitment of workers to see the world of work beyond the boundaries of personal interests in the interests of the organization (Seen,2012).

Transformational leadership is the teacher's assessment of the principal's behaviour that can inspire his subordinates (teachers) to commit to the school's vision, communicate it, motivate, direct, empower, become a model, develop teacher potential and have a new perspective in solving problems. Thus a teacher's principal who has a high-quality transformational leadership will also improve teacher performance to be more optimal in carrying out their duties.

The results of previous research studies have proven that transformational leadership has a positive relationship with performance, the results show that there is a direct and positive influence of transformational leadership $\left(\mathrm{X}_{1}\right)$ on teacher performance $\left(\mathrm{X}_{5}\right)$ with a path coefficient $\left(\mathrm{p}_{\mathrm{x} 5 \mathrm{x} x}\right)$ of 0.50 , culture organization $\left(\mathrm{X}_{2}\right)$ to teacher performance $\left(\mathrm{X}_{5}\right)$ with a path coefficient $\left(\mathrm{p}_{\mathrm{x} 5 \times 2}\right)$ of 0.10 and organizational climate $\left(\mathrm{X}_{3}\right)$ to teacher performance $\left(\mathrm{X}_{5}\right)$ with a path coefficient $\left(\mathrm{p}_{\times 5 \times 3}\right)$ of 0.11 . Based on the results of the study concluded that teacher work performance could be improved through transformational leadership, organizational culture, organizational climate and teacher job satisfaction.

Based on the previous presentation it can be concluded that transformational leadership has a significant contribution in stimulating various performance activities, so the implication is that school principals need to carry out transformational leadership activities that support the optimization of teacher learning activities.

\subsection{The Relationship between Work Motivation and Teacher Performance}

Hypothesis testing shows that there is a very significant positive relationship between work motivation and teacher performance. Based on the calculation of the correlation coefficient between work motivation and teacher performance, the value of $r_{y 3}=0.734$, in this case, the strength of this relationship is classified as strong, the results of the significance of the correlation coefficient test obtained the value of $t_{\text {count }}=12.876$ which is greater than $t_{\text {table }}=2.617$ at the significance level 0.01 , it 
means that the strong correlation value makes work motivation variable has a very significant correlation with teacher performance.

Based on the results of this study, the contribution of work motivation to teacher performance can be seen from the coefficient of determination $\mathrm{r}_{\mathrm{y} 3}^{2}=0.539$, which means that work motivation contributes $54 \%$ to teacher performance, while the remaining $46 \%$ is determined by other variables. The magnitude of this correlation coefficient shows the strength of the relationship between work motivation and teacher performance is relatively high, and referring to the results of the analysis of research data it can be said that increasing the strength of work motivation will be related to improving teacher performance.

Work motivation is a force that moves a person to work. Motivation can be divided into two types, namely: (1) intrinsic motivation, namely the type of motivation whose source comes from within the person concerned, and (2) extrinsic motivation is the type of motivation whose source comes from the environment of the person concerned. When viewed in the practice of carrying out tasks, intrinsic motivation is more positive because usually the results are more optimal and can last longer than extrinsic motivation. However, extrinsic motivation can be given by the teacher itself by managing the situation and conditions of the task so that it becomes more conducive (Robin,2016).

Every work done by someone is always driven by the motives that exist in every human being, both motivation that comes from outside (extrinsic) and motivation that comes from within (intrinsic). However, it should be understood that external motivation or extrinsic motivation that causes a teacher to work sometimes does not guarantee that the motivation can be convincing because the motivation tends to be done because of the strength of the rules so that a teacher can carry out the task. The combination of outside motivation and motivation from inside the teacher to do work can strengthen his drive to work well. The stronger a person's motivation for a job, the stronger the teacher works so that teachers who have high work motivation tend to show high performance as well.

Organizational mechanisms, team mechanisms, and individual characteristics build individual mechanisms in an effort to foster job performance and organizational commitment. Where in the individual mechanism, there is an element of motivation. In addition, this research is also in accordance with the theory said by Uhl-Bien (2014) which says that a person's performance will be effective if influenced by five factors, namely self-esteem, past experience, actual situation, the personality of each individual, and relationships with others. Personality factors of each individual in it including work motivation (Rajiani,2011) .

The results of this study are also consistent with previous studies, which show that there is a positive and significant relationship between organizational culture, transformational leadership, and work motivation together with teacher performance with a correlation coefficient $\mathrm{r}_{\mathrm{y} .123}=0.562$.

Based on the previous explanation, it can be concluded that work motivation has a significant influence in stimulating various teacher performance activities so that the implication is that principals through intensive supervision can influence teacher performance.

\subsection{The Relationship between Organizational Culture, Transformational Leadership and Work Motivation with Teacher Performance}

Hypothesis testing shows that there is a very significant positive relationship between organizational culture, transformational leadership, and work motivation together with performance as evidenced by the regression equation $\hat{Y}=23.45+0.36 x_{1}+0,23 X_{2}+0,27 X_{3}$. The results of the calculation of the correlation coefficient between organizational culture, transformational leadership and work motivation together with teacher performance, obtained the value of $r_{y 123}=0.835$, this value indicates a very strong level of relationship. This means that organizational culture variables, transformational leadership and work motivation together have a very significant correlation with teacher performance.

Based on the results of this study, the contribution of organizational culture factors, transformational leadership and work motivation together on teacher performance can be seen from the coefficient of determination $\mathrm{r}_{\mathrm{y} 1.2 .3 .}=0.697$, which means that organizational culture, transformational leadership and work motivation together contribute $70 \%$ to teacher performance, while the remaining $30 \%$ is determined by other variables. 
According to Rajiani (2010), the findings obtained in this study indicate, if the teacher has a set of values that develop in an organization that helps members of the organization take acceptable and unacceptable actions, the behaviour of a leader who directs his subordinates to use current values towards the vision and the mission that has been set, and the process that directs and encourages activities to achieve good organizational goals, then performance will also improve. Thus a teacher who has a good organizational culture and transformational leadership with the support of good work motivation together will also improve performance.

The tendency that can be seen from the results of this study is the correlation between organizational culture and performance that is $\mathrm{r}_{\mathrm{y} 1}=0.786$ when compared with the correlation between transformational leadership and performance that is $r_{\mathrm{y} 2}=0.734$ and the correlation between work motivation with a performance that is $r_{\mathrm{y} 3}=0.734$ then it appears that culture organization is above the two independent variables, but each or together these three variables can contribute to improving performance. The results of this study indicate that organizational culture is a determining factor for the realization of positive attitudes that teachers have regarding various aspects related to work outcomes. Transformational leadership factors and work motivation are also determinants of teacher performance. Thus it can be seen that the factors of organizational culture, transformational leadership, and work motivation are important things that can continue to be developed so that the value of performance will also increase, for the realization of organizational goals. However, the correlation coefficient becomes higher if the three variables namely organizational culture, transformational leadership and work motivation together with performance variables, namely the correlation coefficient between organizational culture and transformational leadership $\mathrm{r}_{1.2}=0.816$, the correlation coefficient between organizational culture and work motivation $r_{1.3}=0.823$ and the correlation coefficient between transformational leadership and work motivation $r_{2.3}=0.797$. This implies that organizational culture, transformational leadership, and work motivation together are factors in achieving maximum performance. The relationship is further elaborated through the scientific identification theory to conduct operation research in education management as postulated by Hardhienata ( 2017).

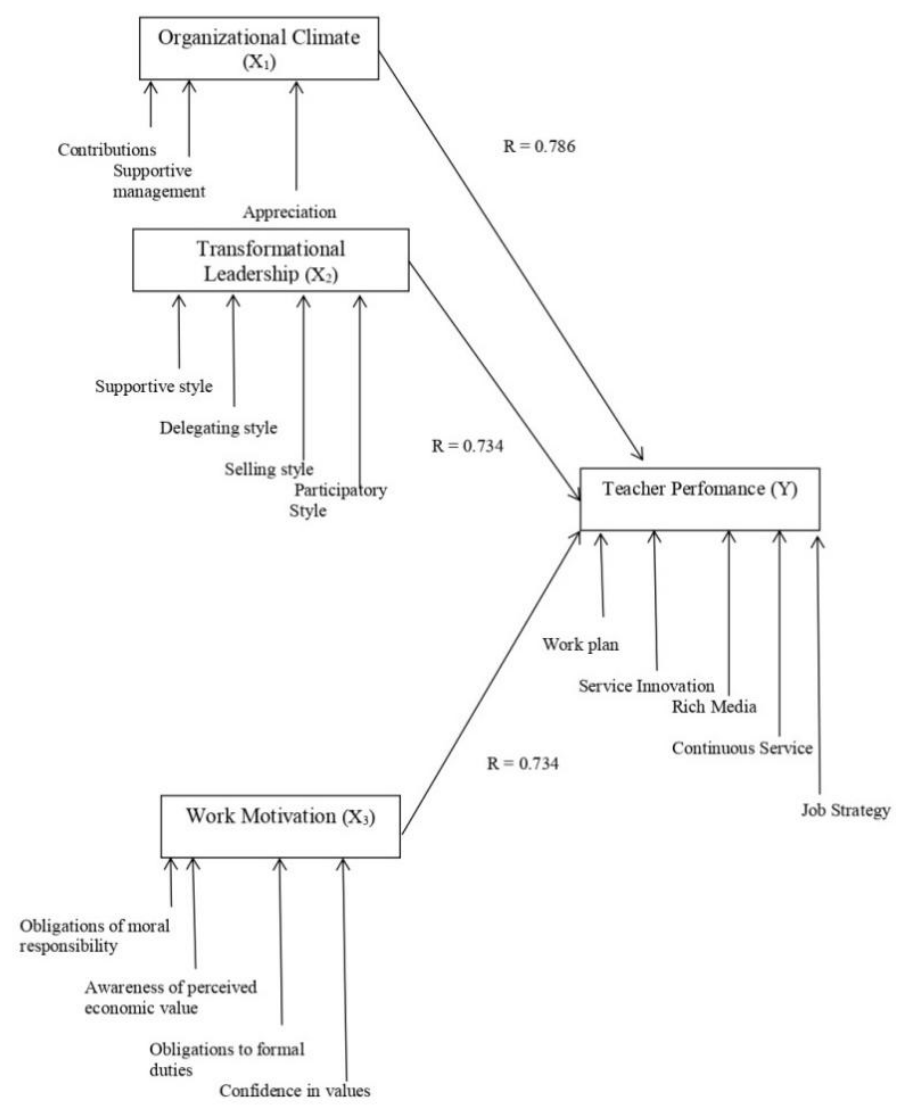

Figure1. Analysis of SITOREM (Scientific Identification Theory for Operational Research in Education) 


\section{CONCLUSION}

After conducting the quantitative research phase through the process of analyzing the results of data processing, statistical calculations, testing hypotheses and discussing the results of research which are then strengthened by the qualitative research stage through the process of observation, in-depth interviews and document collection, the research on the relationship of organizational culture, transformational leadership, work motivation with the performance of Junior High School teachers in South Jakarta produces conclusions detailed as follows:

1. There is a positive relationship between organizational culture and teacher performance through the correlation coefficient of $r_{y 1}=0.786$ and the coefficient of determination $r_{y 12}=0.618$. Thus it can be stated that the better the organizational culture of a teacher, the higher the teacher's performance.

2. Transformational leadership is a positive relationship with the performance of teachers with a correlation coefficient of $r_{\mathrm{y} 2}=0.734$ and determination coefficient $r_{\mathrm{y} 2}{ }^{2}=0.539$. Thus the better the transformational leadership the principle applies to a teacher, the higher the teacher's performance level is.

3. There is a positive relationship of work motivation with teacher performance with a correlation coefficient of $r_{y 3}=0.734$ and a coefficient of determination ry $_{3}{ }^{2}=0.539$. Thus the higher the work motivation of a teacher, the higher the teacher's performance level.

4. There is a relationship between organizational culture, transformational leadership and work motivation together with teacher performance with the correlation coefficient $r_{y .123}=0.835$ and the coefficient of determination $r_{y \cdot 1.2 .3^{2}}=0.697$. Thus the better the organizational culture of a teacher, the better the transformational leadership that a principle applies to a teacher, and the higher the motivation of a teacher's work together with the higher the teacher's performance level.

\section{REFERENCES}

[1] Adeniji, A. A. (2011). Organizational climate as a predictor of employee job satisfaction: Evidence from Covenant University.Business intelligence journal, 4(1), 151-166.

[2] Bertocci, D. I. (2010). Leadership in organizations: There is a difference between leaders and managers University Press of America.

[3] Dawson, P., \& Andriopoulos, C. (2014). Managing change, creativity and innovation.Sage.

[4] Dele, A. O., Ezekiel, A. O., \&Alani, L. F. (2015). Strategic human resource management and organizational climate in the Nigerian Banking Industry. American Journal of Environmental Policy and Management, 1(3), 38-50.

[5] George, J. M., Jones, G. R., \& Sharbrough, W. C. (2015).Understanding and managing organizational behaviour. Upper Saddle River, NJ: Pearson Prentice Hall.

[6] Gibson, J. L., Ivancevich, J. M., Donnelly, J. H., \&Konopaske, R. (1991). Organizations: Behavior, structure, processes. Homewood, IL: Irwin.

[7] Hardhienata, S., 2017.The development of scientific identification theory to conduct operation research in education management. In IOP Conference Series: Materials Science and Engineering (Vol. 166, No. 1, p. 012007). IOP Publishing.

[8] King, D. D., Newman, A., \& Luthans, F. (2016). Not if, but when we need resilience in the workplace. Journal of organizational behaviour, 37(5), 782-786.

[9] Seen, N. Y., Singh, S. K. G., \& Jayasingam, S. (2012). Organizational culture and innovation among Malaysian employees. The Journal of Human Resource and Adult Learning, 8(2), 147.

[10] Rajiani, I., \&Jumbri, I. A. (2011). A cultural ecology of new public management in Indonesia. Journal of Administrative Science, 8(1), 17-31.

[11] Rajiani, I. (2010). Applying Personality Traits to Predict Loyalty and Neglect among Employees of Bank Jatim Located in 10 Big Cities of East Java (McCrae's and Hofstede's Theories on effect of Culture to Personality Revisited). JurnalAplikasiManajemen, 8(3), 617-622.

[12] Robbins, S. P., \& Judge, T. A. (2016).Organizational Behavior, Global 17th Edi- tion.

[13] Uhl-Bien, M., Schermerhorn Jr, J. R., \& Osborn, R. N. (2014). Organizational Behavior, Experience Grow Contribute. 222 Rosewood Drive, Danvers, MA 01923: Clearance Center. 
Improving Teacher Performance through Organizational Culture, Transformational Leadership and Work Motivation

[14] Warren, S. M. (2015). The leadership process: An analysis of follower influence on leader behaviour in hospital organizations(Doctoral dissertation, Pepperdine University).

Citation:Adi Dasmin, et.al., "Improving Teacher Performance through Organizational Culture, Transformational Leadership and Work Motivation " International Journal of Managerial Studies and Research (IJMSR), vol 8, no. 7, 2020, pp. 33-40. doi: http:// dx.doi.org/10.20431/2349-0349.0807004.

Copyright:@ 2020 Authors. This is an open-access article distributed under the terms of the Creative Commons Attribution License, which permits unrestricted use, distribution, and reproduction in any medium, provided the original author and source are credited. 